Dept. of Surgery,

Fac. Vet. Med., Assiut Univ.

Head Prof. Dr. M. Nassef

\title{
CHLORAL HYDRATE AS A PREANAESTHETIC, NARCOTIC AND ANAESTHETIC FOR DONKEYS
}

(With 2 Tables \& 12 Fig.)

\section{By}

H.A. YOUSSEF; S.M. SELIEM and D. TAHA*

(Received at 21/4/1993)

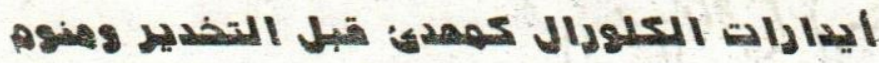 \\ La}

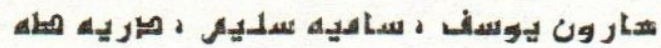

أجريت مذه الدراسه على ع Y حمارئ ، حيث نوقثت النتائم الأكلينيكيه والتأثيرات

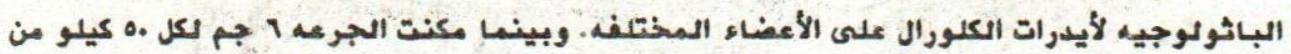

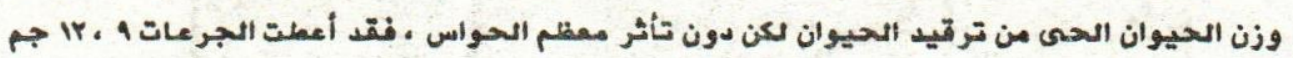

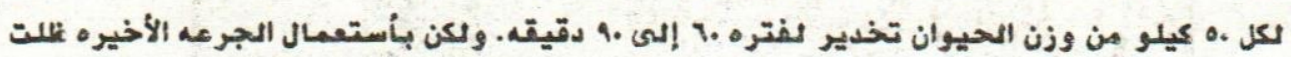

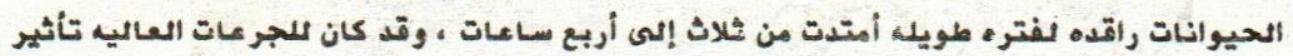

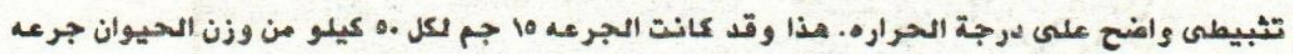

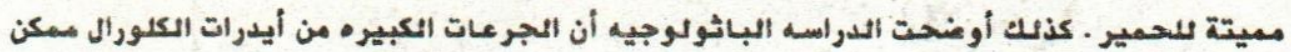

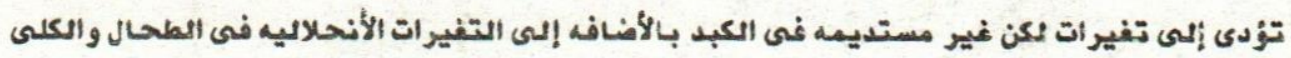
والقلب.

«: Vet. Med. Directorate, Assiut.

Assiut Vet. Med, J. Vol. 22, No 58, July 1993. 


\section{SUMMARY}

The present study was conducted on 24 donkeys to evaluate chloral hydrate as a preanaesthetic, narcotic and anaesthetic drug. The clinical results were discussed and the pathological effects on the parenchymatous organs and brain were also evaluated. Chloral hydrate in a dose rate of $6 \mathrm{~g} / 50 \mathrm{~kg}$ body weight enabled to control donkeys in the recumbent position, but most reflexes were not affected in most animals. The drug in a dose rate of 9 and $12 \mathrm{~g} / 50 \mathrm{~kg}$ body weight gave anaesthesia for a period of 60 to 90 minutes, but with the later dose the animals laid down for a long period ( 3 to 4 hours). The large doses have also severe hypothermic effect. Chloral hydrate in a dose rate of $15 \mathrm{~g} / 50 \mathrm{~kg}$ body weight was lethal for donkeys. The histopathological results showed that the large doses of chloral hydrate may lead to reversible changes in the liver, haemocidrosis in the spleen and focal degenerative changes in the kidneys and heart.

\section{INTRODUCTION}

Despite the advances which have been made in the development of new narcotics for horses, chloral hydrate remains the best one. The drug could be used to induce basal narcosis varying in depth from a light stupor to complete general anaesthesia (HALL, 1971). While chloral hydrate has lost much of its popularity as a general anaesthetic in large animals, yet it is still used guite extensively. Its continued. use in horses depends on the simplicity and on the duration of the effect of the induction dose, an interval adequate for many rout in procedures (LUMB and JONES, 1973).

The use of chloral hydrate alone or with other drugs as a preanaesthetic, narcotic or anaesthetic for horse, was indicated by many authors (BRANDER and PUGH, 1971; HALL, 1971; LUMB and JONES, 1973; JONES, et al, 1977; GREEN, 1979; TRAIMONGKOLKUL, 1979; WHOELER, et al, 1980; BEUTTLER, 1981; CRISPIN, 1981; DIETZ and WIESNER, 1984; DAHYA, et al, 1985; AKPOKODIE et al, 1986; SCHNEIDER and STIEF, 1987 and SHORT, 1987). The use of chloral hydrate in donkeys was recorded by TANTAWY (1980) and SAMY et al (1986).

The present study was designed for reapprasial of chloral hydrate as a preanaesthetic, narcotic and anaesthetic for 
donkeys. The pathological effect on the parenchymatous organs and brain was also discussed.

\section{MATERIALS AND METHODS}

The present study was conducted on 24 apparantly heal thy, 4 to 11 months-old-donkeys. Animals were divided into 4 equal groups; each of 6 animals.

Group I: The animals received $6 \mathrm{~g} .50 \mathrm{Kg}$ BWt. chlotal hydrate. Group II: The animals received $9 \mathrm{~g} / 50 \mathrm{Kg}$ BWt. chloral hydrate. Group III: The animals received $12 \mathrm{~g} / 50 \mathrm{Kg}$ BWt. chloral hydrate. Group IV: The animals erceived $15 \mathrm{~g} / 50 \mathrm{Kg}$ BWt. chloral hydrate.

Chloral hydrate was prepared as $10 \%$ solution and administered intravenously. Heart rate, respiratory rate, and rectal temperature were recorded before and after injection of chloral hydrate and the results were tabulated. Various reflexes (skin reflex, eyelid reflex, coronary hand reflex, conjunctival reflex, corneal reflex anal reflex and tongue withdrawal reflex) were evaluated. The period after which the animals laid down and the duration of narcosis and anaesthesia were also recorded.

Liver biopsy was taken surgically 3 hours after chloral hydrate injection through a midline laparotomy. The line of incision was infiltrated with $2 \%$ procaine $\mathrm{Hcl}$ solution.

Euthanasia 7 days after drug administration was performed by bleeding after exposure of the common carotid artery under effect of local infltration analgesia. The postmortem examination was done immediately after euthanasia, and the macroscopical findings were recorded. For the histopathological study, specimens were collected from the liver, kidneys, spleen, heart, adrenals, lung and brain. Paraffin sections were stained with Haematoxylin and Eosin and examined with the light microscope and the results were recorded.

Animals of both groups I and II were divided into two subgroups $A \& B$ where the drug was used either as non repeated dose or as repeated doses with 7 days intervals for three times. Animals of group IV were divided into two sub groups (A\&B) where the drug was used either with or without atropine premedication. Atropine sulphate $1 \%$ solution was used in a dose of $0.05 \mathrm{mg} / \mathrm{Kg}$ BWt., intramuscularly, 15 minutes before chloral hydrate injection.

\section{RESULTS}

Group I: Animals of This group lied down 2-3 minutes after chloral hydrate $(6 \mathrm{~g} / 50 \mathrm{~kg}$. BWt. $)$ injection. The skin reflex, eyelid, conjunctival and coronary band reflexes disappeared in some animals 15 minutes after chloral hydrate injection and Assiut Vet. Med. J. Vol. 29, No. 58, 1993. 
rappeared within 45 minutes. Tongue withdrawal reflex disappered after 15 minutes and reappeared 60 minutes after drug injection in all animals. The animals stood up 45 to 80 minutes after administration of the drus.

Group II: The animals of this group lied down just after administration of chloral hydrate $(9 \mathrm{~g} / 50 \mathrm{~kg}$ BWt.). The skin reflex, coronary band reflex and eyelid reflex disappeared within 15 minutes and reappeared within 60 to 75 minutes after drug administration. The corneal reflex and anal spincter contraction only sluggished after 30 minutes and returned completely within 60 to go minutes. Within 2 to 3 hours after the drug administration, the animals could stand up.

Group III: The animals of this group lied down during injection of chloral hydrate $(12 \mathrm{~g} / 50 \mathrm{~kg} \mathrm{BWt}$,$) . The reflexes$ disappeared within 10 minutes and reappeared within 90 to 120 minutes after injection of chloral hydrate. The animals were able to stand up within 3 to 4 hours after drug administration.

Group IV: The reflexes disappeared within 10 minutes and reappeared within 3 hours after chloral hydrate administration $(15 \mathrm{~g} / 50 \mathrm{~kg}$ BWt. $)$ in 2 animals. The animals began trials to stand up within 4 hours but were able to stand up 6 hours after drug injection. Three animals (two of them were premedicated with atropine) died within 10 minutes after chloral hydrate injection. One animal (premedicated with atropine( died after 105 minutes.

The changes in the body temperature, heart rate and respiratory rate are shown in tables (1\&2) and figures $(1,2,3,4,5 \& 6)$.

The postmortem examination revealed only petecheal haemorrhages in the spleen of in one animal 7 days after chloral hydrate administration in a dose rate of $9 \mathrm{~g} / 50 \mathrm{~kg}$ Bwt. (Fig. 7). On microscopic examination of the liver of all groups, the pathological alterations were restricted to the centrilobular zones and ranged from parenchmatous degeneration to hydropic and vascular degeneration. The cytoplasm showed coarse acidophilic granules and empty vacules (Fig. 8). The hepatic cords were distorted and hepatocytes were swollen (Fig. 9). The heart showed focal degenerative and necrobiotic cganges in group III and IV (Fig. 10). The kidneys in one case (group III) showed degenerative and necrobiotic changes (Fig. 11). .

The spleen showed haemosidrosis in all group (Fig. 12). The brain and adrenals showed no microscopic detectable changes.

\section{DISCUSSION}

When chloral hydrate was used in donkeys, anaesthesia was obtained with a dose rate ranging from 9 to $12 \mathrm{~g} / 50 \mathrm{~kg} \mathrm{BWt}$. When Assiut Vet. Med. J. Vol. 29, No. $58,1993$. 
the sub-anaesthetic doses $(6 \mathrm{~g} / 50 \mathrm{~kg}$ BWt.) were used, some of the reflexes remained unaffected, some sluggished and some disappeared for a short time in comparison to the long recumbency time. JONES et al. (1977) recorded that this may be attributed to the very weak analgesic action of chloral. hydrate. Although a good anaesthesia for 60 to 90 minutes was obtained with the use of chloral hydrate in donkeys, the anaesthetized animals took a long time (3-4 hours) to be able to stand up.

While the body temperature decreased following adminstration of chloral hydrate for donkeys, the heart was accelerated. The respiratory rate was accelerated, then fluctuated around the original values and lastly decreased.

While it was repoted by some authors that chloral hydrate may result in degenerative changes in the liver (HALL, 1971, GREEN, 1979 and AGRAWAL et al, 1983), JONES et al (1977) stated that the drug has little or no deterimental effect upon liver in the absence of hypercapnia and hypoxia. In donkeys the changes in the liver after chloral hydrate administration were reversible.

The constant findings after administration of large doses of chloral hydrate were haemocidrosis in the spleen and focal degenerative changes in the kidneys and heart. These changes may be related to the use of the drug in high doses. On the contrary the petecheal haemorrhages which were detected in the spleen in one case may be due to parasitism. The drug seemed to cause no detectable changes in the adrenals or brain.

\section{ACKNOWLEDGMENTS}

The present study was performed with the kind advice of Prof Dr. M. EL-GUINDY, Dept of Surgery and Prof. Dr. A. BAYOUMI, Dept. of Pathology, Fac. Vet. Med., Assiut University.

\section{REFERENCES}

Agrawal, K.B.P; Prasad, B. and Sobti, V.K. (1983)b: Histopathological observations after administration of glyceryl guaiacolate with and without chloral hydrate/thiopental sodium in buffalo-calves. Indian $\mathrm{J}$. Vet. Surg. 4(2): 64-69.

Akpokodje, J. U; Akusu, M.O. and Osuagwa, A.I.A. (1986): Abortion of twins following chloral hydrate anaesthesia in a mare. Vet Record, 118 (11): 306-307.

Beuttler, J.(1981): Blood pressure measurement in the horse under various anaethetics. Inaugural dissertation, Tierazliche Hochschule, Hochschule, Hannover. Abstract,

Assiut Vet. Med. J. Vol. 29, No. 58, 1993. 
Vet. BULL. 1453 (Vol. 53, No. 2, 1983).

Brander, G.C. and Pugh, D.M. (1971): Veterinary applied pharmacology and therapeutics. Bailliere Tindall. London.

Second ed., P. 248-251.

Crispin, S.M. (1981): Methods of equine general anaesthesia in clinical practice. Equine Vet. J. 13 (1): 19-26. Abstract, Vet, Bull. 5267 (Vol., 51, No. 1981).

Dahya, Z.S; Peshin, P.K; Nigam, J.M. and Chawla, S.K. (1985): Evaluation of promazine and chloral hydrate anaesthesia in horses. Indian Journal of animal sciences 55 (4): 243-248. Dietz, O. and Wiesner, E. (1984): Diseases of the horse. S. Karger. Basel. Munchen. Paris. London. Newyork. Tokyo. First English ed., Part 1, P. 69.

Green, C. J. (1979): Animal anaesthesia, Laboratory Animals. LTD London. First ed. , P. 79-139.

Hall, L. W. (1971): Veterinary anaesthesia and analgesia. Seventh edition, Bail-liere Tindall. London. Sevent ed. P. , 171-300. .

Jones, L. M.; Booth, N.H. and Mc Donald, L. E. (1977): Veterinary pharmacology and therapeutics. Ames: The Iowa State University Press. Fourth ed. , P. 278-306.

Lumb, W.V. and Jones, E.W. (1973): Veterinary anaesthesia. Lea and Febiger, philadelphia. Second ed., 209-478.

Samy, M. T; El-Sehaie, A. and Aly, M. A. (1986): Blood gases and acid-base balance under the inflince of different anaesthetic combination in donkeys. Assiut Vet. Med. J. 17 (33): 147-154.

Schneider, J. and Stife, E. (1987): Behaviour of some measures of acid-base equilibrium, heart rate and depth of anaesthesia during chloral hydrate and chloral hydrate/ My-30 anaesthesia in the horse. Archiv Fur Experimentelle Veterinarmedizin 41 (2): 276-384.

Short, C.E. (1987): Principles and practice of veterinary anaesthesia. Williams \& Wilkins, Baltimore, London, Los Angeles and Sydney. First ed., P. 24-25.

Tantawy, M. (1980): The clinical use of a combination of Combelen and chloral hydrate anaesthesia in donkey. Vet. Med. Rev. (2): 175-177.

Traimongkolkul, T. (1979): Behaviour of blood gases, blood pressure and acidhase equilibrium during anaesthesia of horses with chloral hydrate, guaifenesin and methitural. Inaugural Disserrtation, Tierarztliche Hochschule, Hannover. Abstract, Vet. Bull, (Vol. 50, No. 9, 1980). Whoeler, J.T. Mollo, M.G; Balladares, G.H. and Provenzal, P. (1980): General anasthesia in horses with thiopental

Assiut Vet. Med. J. Vol. 29, No. 58, 1993. 
sodium in combination with chloral hydrate and procaine. Gaceta Veterinaria, 42 (356): 776-666. Abstract Vet. Bull., 7062 (Vol. 51, No. 11, 1981).

Table (1): Showing the mean values of the body cemperature, heart rate and respiracory rate after injection of chloral hydrate in donkeys.

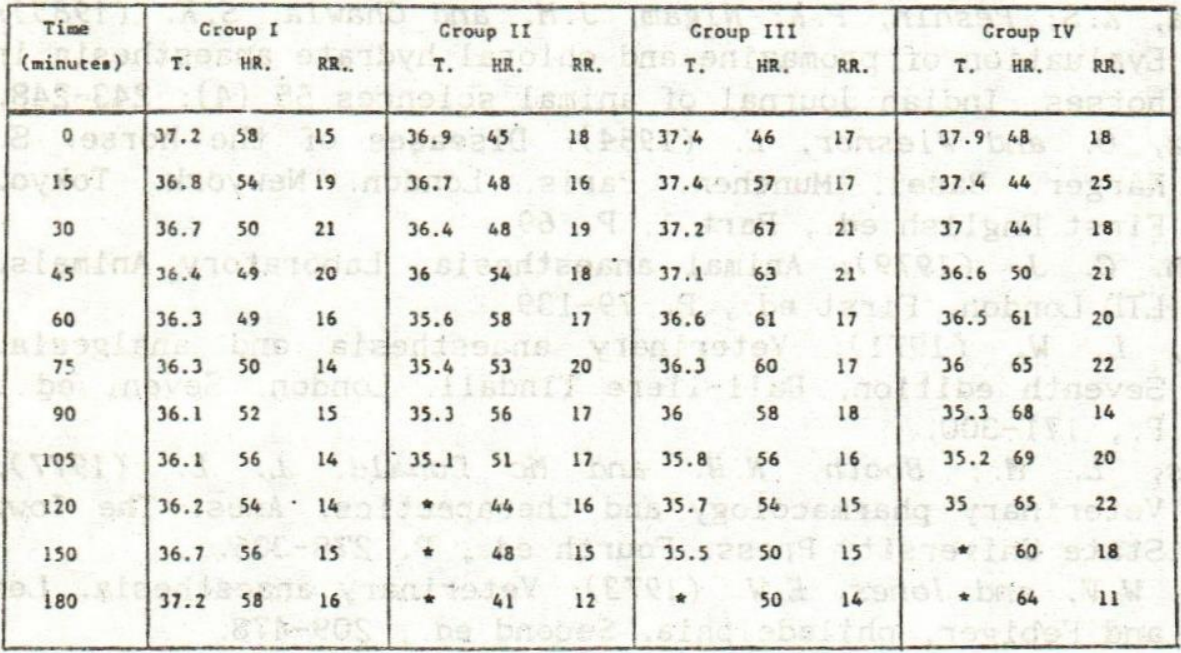

T. Body temperature.

RR. Respiratory rate.
HR. Heart rate.

- Lowe $z$ than 35 degree centigrade.

Table (2): Showing the mean values of the body temperature, heart rate and respiratory rate after ijection of chloral hydrace (repeated doses) in dokeys.

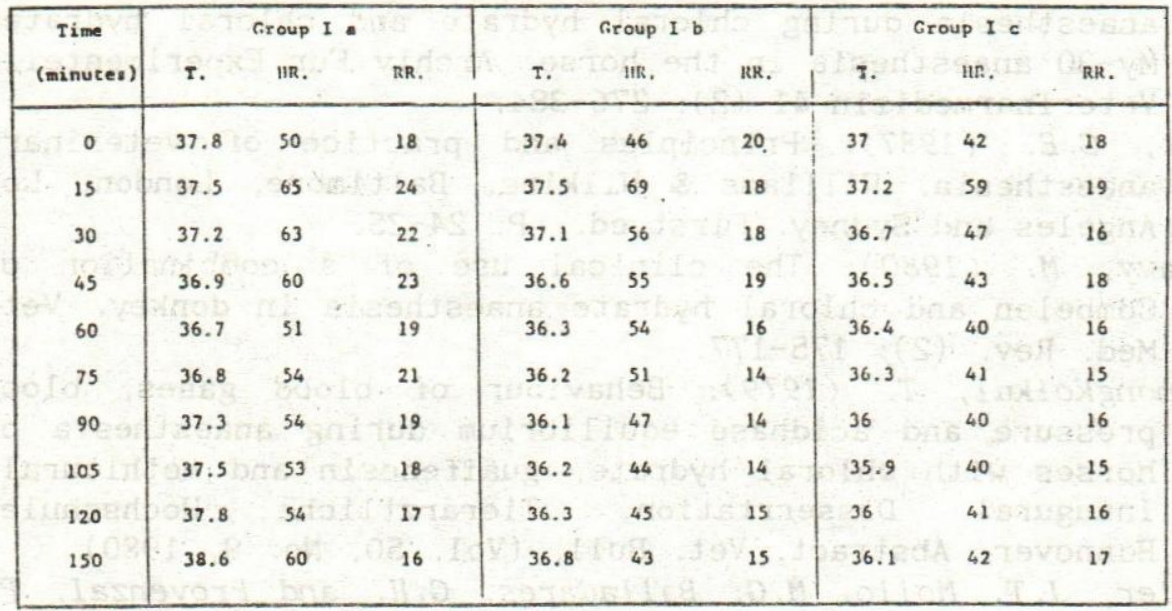

I. Body temperature.

HR. Heart rate.

RR. Respiratory rate.

Assiut Vet. Med. J. Vol. 29, No. 58, 1993. 
F1g. (1) uffect of Chioral hyderate an wedy tenperature
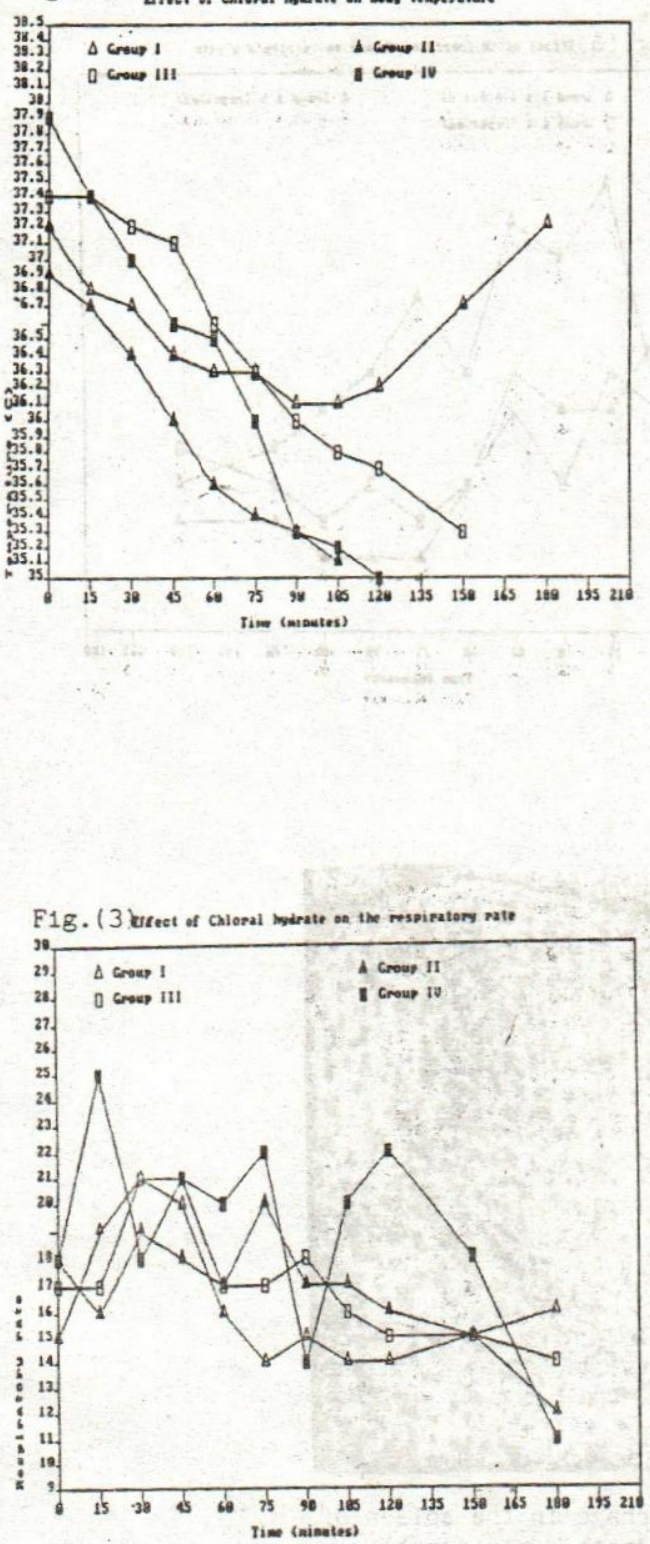

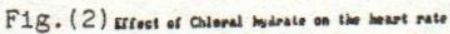
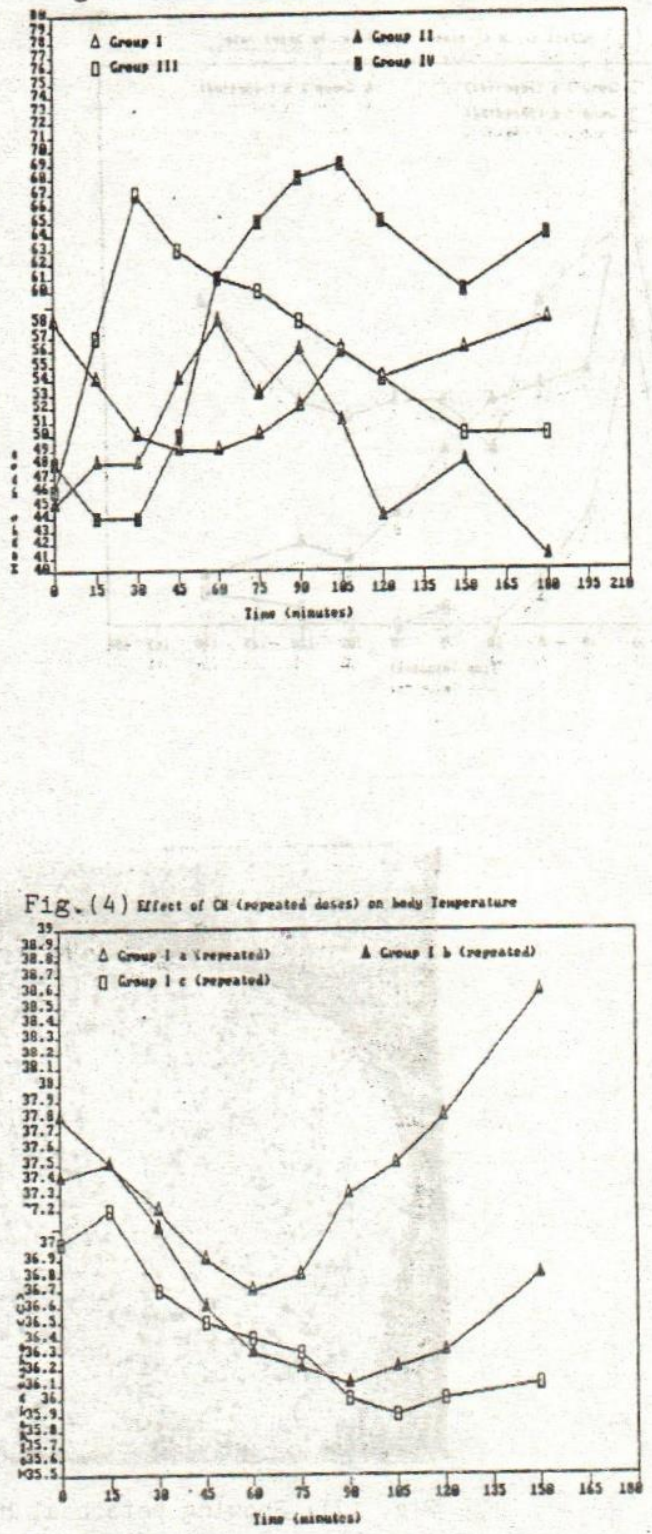

Assiut Vet. Med. J. Vol. 29, No. 58, 1993. 


\section{H. A. YOUSSEF et al.}

F 1 g. $(5)$ gitest of a (-eseeted toces) en the deapt reto

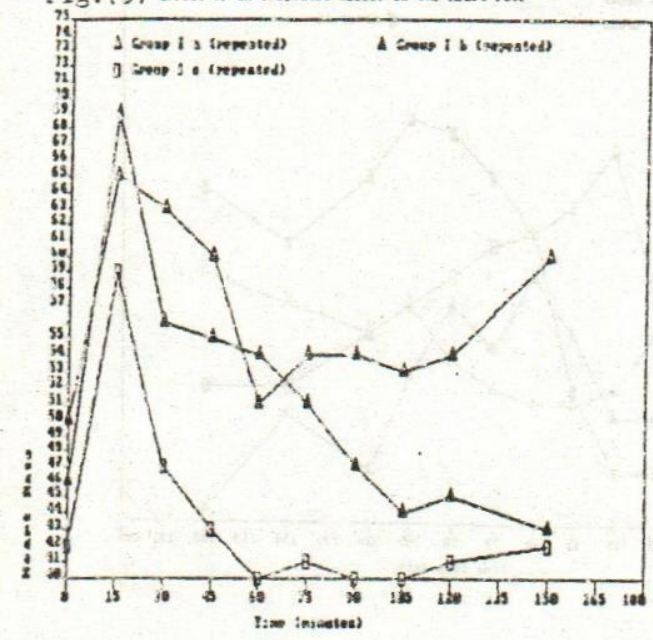

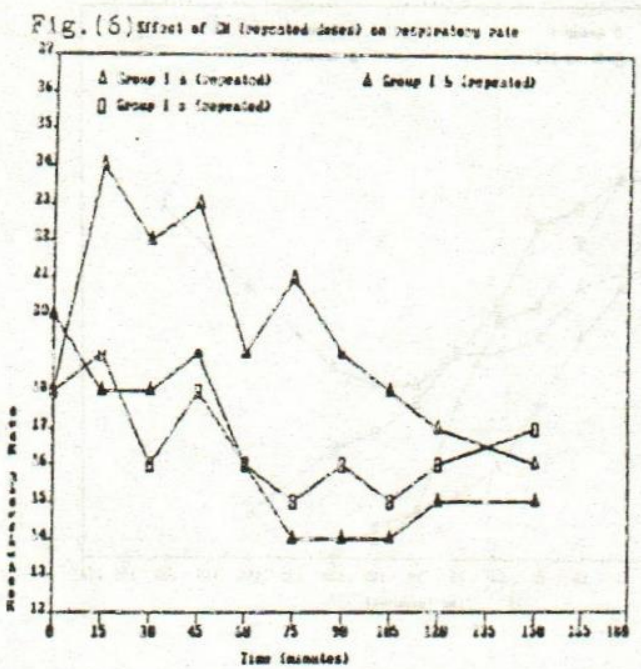

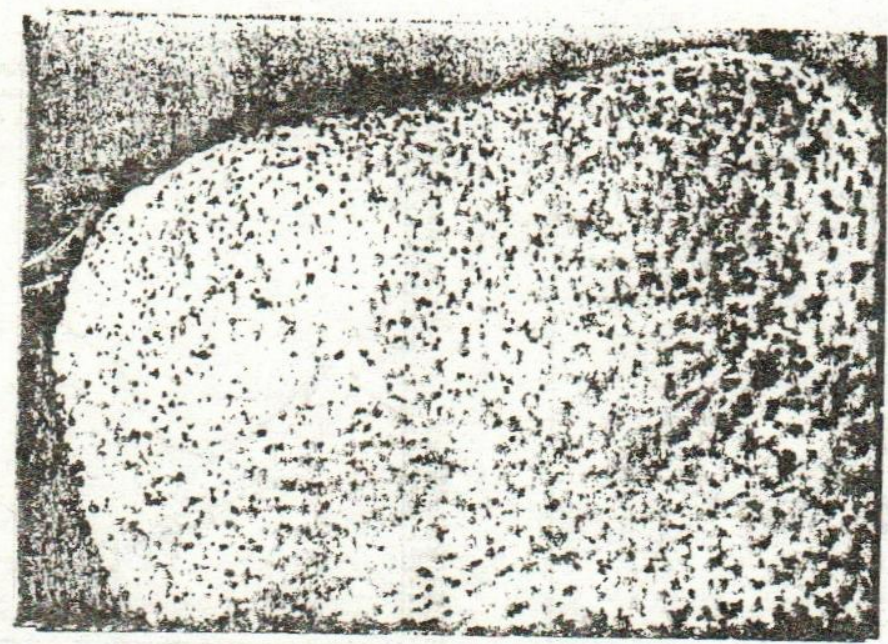

Fig. (7): Showing petacheal haemorrhaze in the 3plean of a junkey, 7 days ifter chloral hydrate admintsiration in a dose rate of jo/jukg body 've! ght. 


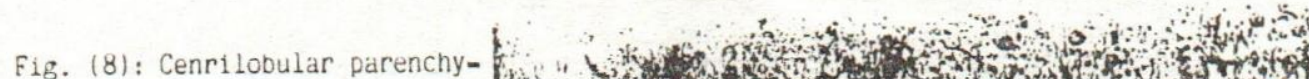
matous degeneration and vaculation in the liver, H\&E (X 400).

Fitr. (y): The Iiver howitur, $d_{1: i}$ Lution of the hepatic cords and swelling of the hepatocytes, H\&E (X 4,00).
Fite. (10): Showluk; myin curdial defeneralive: chatis $20 .$, lisk $(X 400)$.
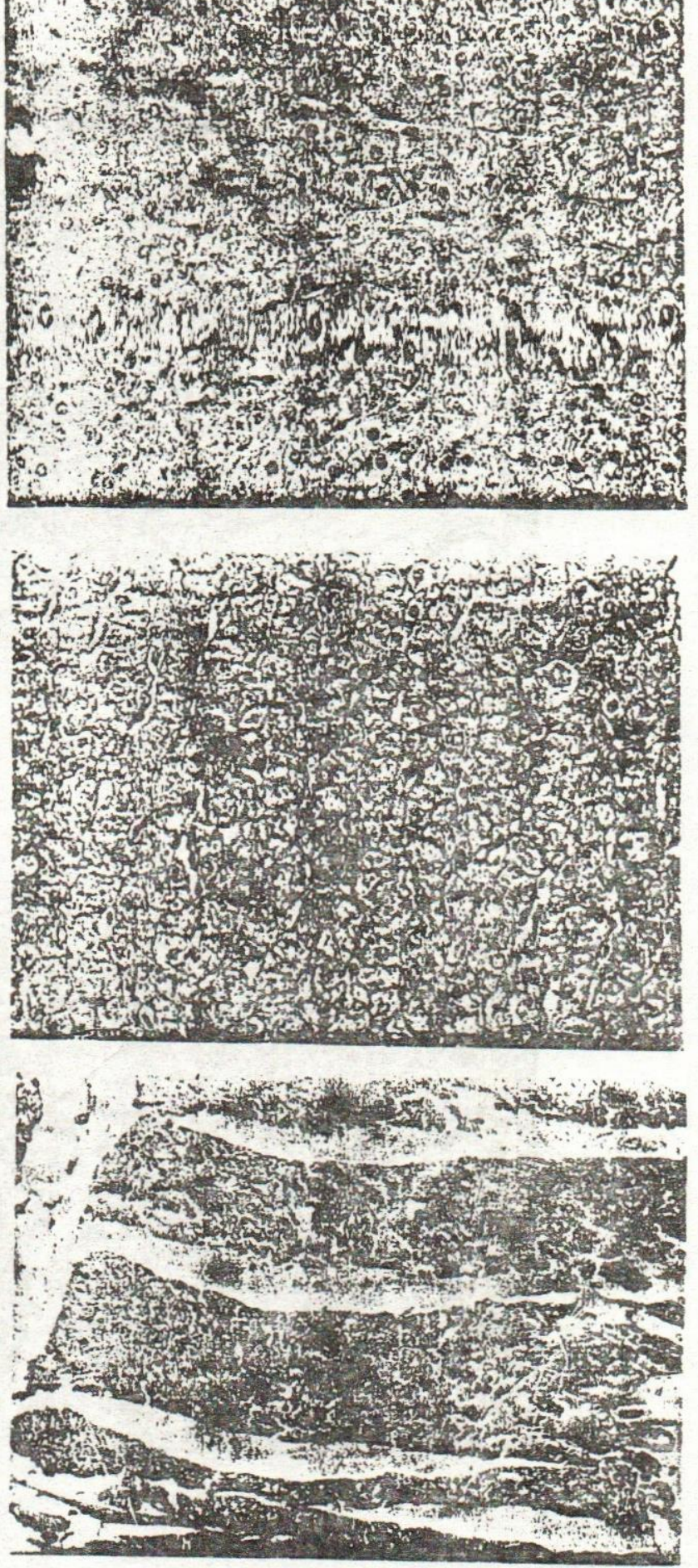

Assiut Vet. Med. J. Vol. 29, No. 58, 1993. 


\section{H. A. YOUSSEF et al.}

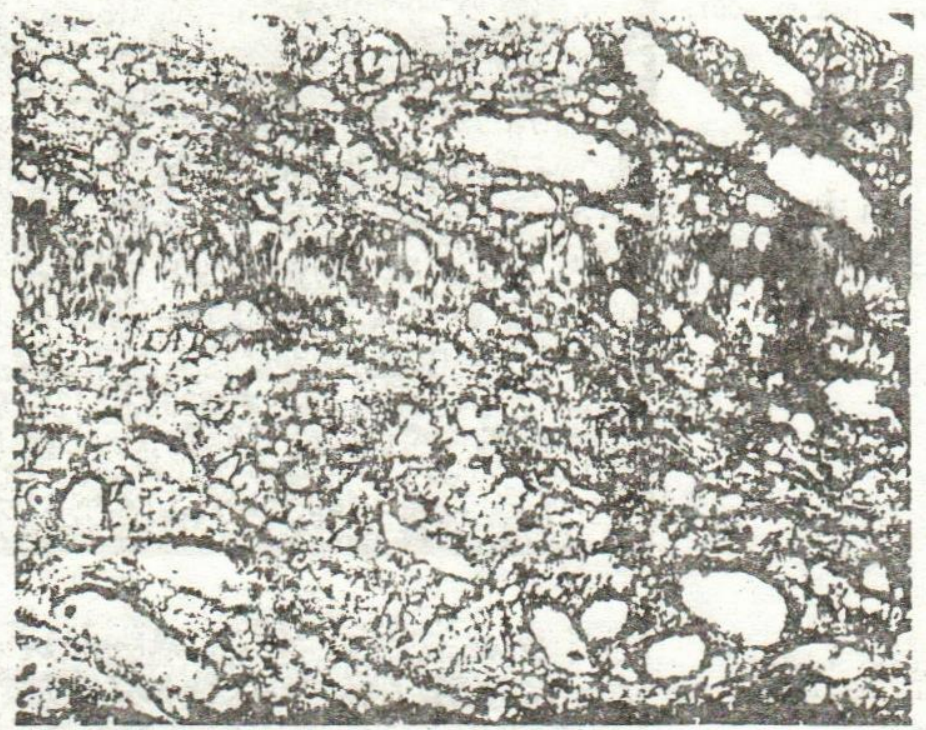

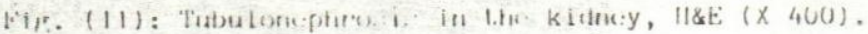

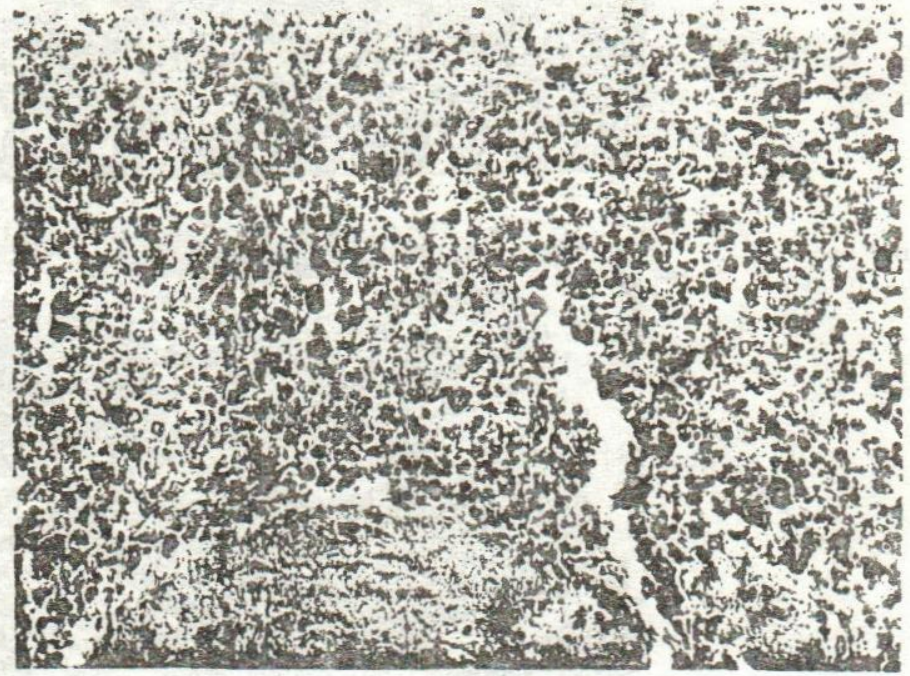

Fig. (12): Haemosidrosis in the spleen, H\&E (X 400). 